\title{
A study to analyze and correlate histopathology of hysterectomy specimen, ultrasonography and clinical presentation in perimenopausal women with abnormal uterine bleeding
}

\author{
Roma Sharma, Achala Sahai \\ Corresponding author: Dr. Achala Sahai, Associate Professor, Department of Obstetrics and \\ Gynaecology, Gajra Raja Medical College, Gwalior, Madhya Pradesh, India; \\ Email : drachalasahai_2@rediffmail.com
}

Distributed under Attribution-Non Commercial - Share Alike 4.0 International (CC BY-NC-SA 4.0)

\begin{abstract}
Background: Abnormal uterine bleeding (AUB) is defined as any variation from the normal menstrual cycle, including changes in regularity and frequency of menses, in duration of flow, or in amount of blood loss. Objectives: To study various USG findings, histopathology of hysterectomy specimens and bleeding patterns in perimenopausal women and to correlate it. Material and methods: It was a prospective observational study done from November 2017 to April 2019 on 250 perimenopausal women (aged 40 years and above till 1 year beyond menopause) with AUB. Results: Maximum number of cases 176 (70.4\%) were in the age group of 40- 45 years. Out of 250 cases 109 cases $(43.6 \%)$ belongs to parity 4 . Majority of cases 136 cases $(54.4 \%)$ presented with menorrhagia. The most common preoperative diagnosis or provisional diagnosis made by clinical examination was of fibroid in 94 cases (37.6\%) followed by polyp and adenomyosis 17 cases. Final diagnosis was made by HPE which showed leiomyoma in 107 cases. USG and HPE showed statistically substantial agreement $(k a p p a=0.647)$ in diagnosis of fibroid with $p$ value $<0.05$ showing that the result was significant. Conclusion: Enhancement in the skill and experience of examiner will go a long way in giving better and more accurate clinical diagnosis of AUB cases for timely intervention and management in perimenopausal women.
\end{abstract}

Keywords: Menorrhagia, fibromyoma, perimenopausal woman.

Abnormal uterine bleeding (AUB) is defined as any variation from the normal menstrual cycle, including changes in regularity and frequency of menses, in duration of flow, or in amount of blood loss. It is just a symptom not a disease. ${ }^{1}$ More than $70 \%$ of all gynecological consultations in the peri and postmenopausal age group is due to AUB. ${ }^{2}$ It occurs in various forms such as menorrhagia, polymenorrhagia, metrorrhagia, and menometrorrhagia.

Dysfunctional uterine bleeding (DUB) is defined as excessive bleeding (excessively heavy, prolonged or frequent) of uterine origin which is not due to demonstrable pelvic disease, complications of pregnancy or systemic disease. ${ }^{3,4}$ It accounts for approximately $50 \%$ of all cases and is ovulatory in almost $80 \%$ of cases. ${ }^{5,6}$

Categories of abnormal uterine bleeding in premenopausal women ${ }^{7}$ -

- Ovulatory abnormal uterine bleeding is usually regular and often associated with premenstrual symptoms and dysmenorrhea.

- Anovulatory abnormal uterine bleeding is common near menarche and the perimenopause; usually irregular, heavy and prolonged. Endometrial hyperplasia and cancer are more likely to be associated with it.

Received: $8^{\text {th }}$ December 2020, Peer review completed: $4^{\text {th }}$ March 2021, Accepted: $7^{\text {th }}$ March 2021.

Sharma R, Sahai A. A study to analyze and correlate histopathology of hysterectomy specimen, ultrasonography and clinical presentation in perimenopausal women with abnormal uterine bleeding. The New Indian Journal of OBGYN. 2022; 8(2): 257 - 61. 
The New Indian Journal of OBGYN. 2021 (January-June);8(2)

Aims and objectives

- To study various ultrasonography (USG) findings, histopathology of hysterectomy specimens and bleeding patterns in perimenopausal women.

- To analyze and correlate the above 3 parameters.

\section{Material and methods}

It was a prospective observational study done at Kamla Raja Hospital, G.R. Medical College, Gwalior (MP) for study period from November 2017 to April 2019. Total sample size was 250 women.

Inclusion criteria -

- Perimenopausal women age group of 40 years and above till 1 year beyond menopause who were admitted with complaints of AUB

Exclusion criteria -

- Women who were less than 40 years of age having medical disorder like coagulation disease

- Liver disease

- Extragenital malignancy

- Renal disease

- Patients not willing to give consent.

After obtaining informed consent from selected patients, the relevant data such as age, parity, menstrual symptoms (past and present menstrual history), and medical /surgical history was taken followed by general, systemic and gynaecological examination and other associated findings in clinical examination were recorded. Thorough gynaecological examination involving per abdomen, per speculum and per vaginum was carried out and any obvious findings related to cervix, uterus or adnexa were assessed (like cervix hypertrophy, ectopy, presence of polyp, uterine size, position, mobility, tenderness). Following history and examination, investigations including $\mathrm{CBC}$, coagulation profile, thyroid function test, LFT, RFT were done. After all required workup, clinical diagnosis and allocation to PALM COEIN was done.

Besides a thorough history taking and examination in all these women, ultrasonographic evaluation was done to assess uterus (size, polyp, fibroid, adenomyosis, and endometrial thickness) and ovarian status. The clinical presentations and ultrasonographic findings were correlated. Histopathologic report of hysterectomy specimens including endometrial, myometrial, and cervical findings were correlated with sonographic reports, and results were analyzed. Data were expressed as number, percentage and results were analyzed using Graph Pad Software, Inc; Version 3.1.

\section{Results}

Table 1 showed the relation between age and parity, maximum number of cases 176 were in the age group of 40 45 year with parity of 4 and higher. As evident in the study incidence of AUB among perimenopausal age group was maximum in multiparous that too more common in grandmultipara women (109 cases) $43.6 \%$ rest as shown above.

Table 1: Distribution of cases according to age and parity ( $\mathrm{n}=\mathbf{2 5 0}$ )

\begin{tabular}{llllll}
\hline Parity & \multicolumn{3}{c}{ Age in years } & $\begin{array}{l}\text { No. of } \\
\text { cases }\end{array}$ & Percentage \\
\cline { 2 - 5 } & $\mathbf{4 0 - 4 5}$ & $\mathbf{4 6 - 5 0}$ & $>\mathbf{5 0}$ & 2 & 0.8 \\
\hline 0 & 2 & 0 & 0 & 5 & 2 \\
1 & 4 & 1 & 0 & 55 & 22 \\
2 & 45 & 8 & 2 & 79 & 31.6 \\
3 & 54 & 25 & 0 & 109 & 43.6 \\
$>4$ & 71 & 21 & 17 & 9 \\
\hline
\end{tabular}

Table 2 shows that majority of cases presented with menorrhagia as a symptom, which was in about 136 cases (54.4\%) which, in other studies was referred to as heavy menstrual bleeding (HMB), followed by polymenorrhagia which was a common bleeding pattern in 55 cases (22\%).

Table 2 : Distribution of cases according to clinical presentation (n=250)

\begin{tabular}{lll}
\hline Clinical presentations & No. of cases & Percentage \\
\hline Menorrhagia & 136 & 54.4 \\
Metrorrhagia & 17 & 6.8 \\
Polymenorrhea & 20 & 8 \\
Menometrorrhagia & 20 & 8 \\
Dysmenorrhea & 2 & 0.8 \\
Polymenorrhagia & 55 & 22 \\
\hline
\end{tabular}

Table 3: Distribution of cases according to clinical provisional diagnosis and correlation with HPE $(n=250)$

\begin{tabular}{lllllll}
\hline $\begin{array}{l}\text { Clinical } \\
\text { provisional } \\
\text { diagnosis }\end{array}$ & No & $\%$ & \multicolumn{2}{l}{$\begin{array}{l}\text { Confirmed on } \\
\text { HPE }\end{array}$} & Not confirmed \\
\cline { 3 - 7 } & & & No & \% & No & $\%$ \\
\hline Fibroid & 94 & 37.6 & 75 & 79.79 & 19 & 20.21 \\
Adenomyosis & 12 & 4.8 & 6 & 50 & 6 & 50 \\
Both & 3 & 1.2 & 1 & 33.33 & 2 & 67 \\
DUB & 123 & 49.6 & 50 & 40.6 & 73 & 58.87 \\
Polyp & 17 & 6.8 & 16 & 94.12 & 1 & 5.8 \\
Malignancy & 1 & 0 & 1 & 100 & 0 & 0 \\
\hline $\begin{array}{l}\text { HPE - Histopathological } \\
\text { bleeding }\end{array}$ & examination, DUB - Dysfunctional uterine \\
\hline
\end{tabular}

Table 3 depicted that among organic causes of AUB most common preoperative diagnosis or provisional diagnosis made by clinical examination was of fibroid in 94 cases (37.6\%) followed by polyp and adenomyosis in 17 cases. Overall most common provisional diagnosis made was of DUB which in our study accounts for 123 cases (49.6\%). Out of 94 cases which were clinically diagnosed as fibroid, 75 cases $(79.7 \%)$ were confirmed on HPE and 19 cases (20.2\%) had different diagnosis on HPE. Out of 123 diagnosed cases of DUB, 50 cases $(40.6 \%)$ showed no gross pathology in HPE and was confirmed as DUB while rest 73 
cases $(58.8 \%)$ exhibited gross pathology in HPE. In our study malignancy was suspected in only 1 case and was confirmed on HPE.

Table 4: Distribution of cases according to USG diagnosis $(n=250)$

\begin{tabular}{lll}
\hline USG diagnosis & No. of cases & Percentage \\
\hline Fibroid & 122 & 48.8 \\
Adenomyosis & 23 & 9.2 \\
Both & 4 & 1.6 \\
Thickened endometrium & 12 & 4.8 \\
Bulky uterus & 42 & 16.8 \\
Polyp & 11 & 4.4 \\
Malignancy & 0 & 0 \\
Normal & 36 & 14.4 \\
\hline
\end{tabular}

Table 4 shows distribution of cases according to USG diagnosis. Out of 250, USG diagnosed 122 cases as fibroid (48.8\%), 42 cases $(16.8 \%)$ as bulky uterus, 36 cases $(14.4 \%)$ as normal, devoid of any structural / pathological abnormality.

Table 5: Correlation of USG diagnosis and histopathology

\begin{tabular}{lll}
\hline USG diagnosis & $\begin{array}{l}\text { Confirmed on } \\
\text { HPE }\end{array}$ & $\begin{array}{l}\text { Not confirmed } \\
\text { on HPE }\end{array}$ \\
\hline Fibroid $(\mathrm{n}=122)$ & 92 & 30 \\
Adenomyosis $(\mathrm{n}=23)$ & 10 & 13 \\
Both $(\mathrm{n}=4)$ & 0 & 4 \\
Thickened endometrium $(\mathrm{n}=12)$ & 5 & 7 \\
Bulky uterus $(\mathrm{n}=42)$ & 14 & 28 \\
Polyp $(\mathrm{n}=11)$ & 11 & 0 \\
Normal $(\mathrm{n}=36)$ & 27 & 9 \\
\hline
\end{tabular}

Table 5 depicts that clinical diagnosis was confirmed by USG but final diagnosis was made on HPE, out of 122 cases who were diagnosed to have fibroid on USG, 92 cases were confirmed to have leiomyoma on HPE and 30 showed otherwise. USG and HPE showed statistically substantial agreement $(\mathrm{kappa}=0.647)$ in diagnosis of fibroid with $\mathrm{p}$ value $<0.05$ showing that the result was significant (table 6).

Table 6: Statistical correlation between USG and HPE diagnosis

\begin{tabular}{lllll}
\hline USG diagnosis & $\begin{array}{l}\text { True } \\
\text { positive }\end{array}$ & $\begin{array}{l}\text { True } \\
\text { negative }\end{array}$ & $\begin{array}{l}\text { Kappa } \\
\text { (agreement) }\end{array}$ & $\begin{array}{l}\text { P } \\
\text { value }\end{array}$ \\
\hline $\begin{array}{l}\text { Fibroid(n=122) } \\
\text { Adenomyosis(n=23) }\end{array}$ & 92 & 114 & .647 & $<0.05$ \\
$\begin{array}{l}\text { Both(n=4) } \\
\text { Thickened endometrium+ }\end{array}$ & 10 & 119 & .241 & $<0.05$ \\
$\begin{array}{l}\text { bulky uterus + normal } \\
(\mathrm{n}=12+42+36)\end{array}$ & 0 & 234 & .025 & $>.05$ \\
$\begin{array}{l}\text { Polyp(n=11) } \\
\text { Malignancy(n=0) }\end{array}$ & 38 & 146 & .369 & $<0.05$ \\
\hline
\end{tabular}

In regards to diagnosis of adenomyosis USG and HPE showed statistically fair agreement $(k a p p a=0.241)$ with $p$ value $<0.05$ which was significant. Sensitivity of USG in diagnosing fibroid signifies that our test (USG) detected $86.8 \%$ cases correctly as fibroid who actually had fibroid, specificity signifies that our test (USG) detected $79.2 \%$ cases as not having fibroid who were actually not having fibroid. In our study we found that there was $75.4 \%$ (PPV) chances of having fibroid in a person who had fibroid on USG(considering HPE as gold standard) and 89.1\%(NPV) chances of not having fibroid in cases who were not having fibroid on USG (table 7).

\begin{tabular}{|c|c|c|c|c|}
\hline USG diagnosis & $\begin{array}{l}\text { Positive } \\
\text { predictive } \\
\text { value }(\%)\end{array}$ & $\begin{array}{l}\text { Negative } \\
\text { predictive } \\
\text { value }(\%) \\
\end{array}$ & $\begin{array}{l}\text { Sensitivity } \\
(\%)\end{array}$ & $\begin{array}{l}\text { Specificity } \\
(\%)\end{array}$ \\
\hline Fibroid $(\mathrm{n}=122)$ & 75.4 & 89.1 & 86.8 & 79.2 \\
\hline Adenomyosis $(\mathrm{n}=23)$ & 43.5 & 87.7 & 26.3 & 93.9 \\
\hline Both $(n=4)$ & 0 & 95.1 & 0 & 98.3 \\
\hline $\begin{array}{l}\text { Thickened } \\
\text { endometrium }\end{array}$ & & & & \\
\hline $\begin{array}{l}\text { Bulky uterus }+ \\
\text { normal } \\
(\mathrm{n}=12+42+36))\end{array}$ & 42.2 & 91.2 & 73.1 & 73.7 \\
\hline Polyp $(n=11)$ & 90.9 & 95.0 & 45.5 & 99.6 \\
\hline
\end{tabular}

Finally clinical, radiological and histopathology finding of hysterectomised specimen were correlated as show in table 8 , in 94 cases diagnosis of fibroid was made clinically, USG detected fibroid in 122 cases. So USG detected fibroid in $100 \%$ cases who were suspected to have fibroid on clinical examination, final diagnosis was made by HPE which showed leiomyoma in 107 cases, so diagnostic accuracy for fibroid is more as compared to adenomyosis, which had less diagnostic accuracy of clinical and USG diagnosis. In our study Chi square value came to be 89.93 and $\mathrm{P}$ value $<0.05$ shows that there is significant correlation between clinical, USG and HPE diagnosis.

Table 8: Correlation of clinical, USG and HPE

\begin{tabular}{llllll}
\hline Categories & $\begin{array}{l}\text { Clinical } \\
\text { diagnosis }\end{array}$ & USG & HPE & $\begin{array}{l}\text { Chi } \\
\text { square }\end{array}$ & $\begin{array}{l}\text { P } \\
\text { value }\end{array}$ \\
\hline Fibroid & 94 & 122 & 107 & & \\
Adenomyosis & 12 & 23 & 40 & & \\
Both & 3 & 4 & 12 & 89.93 & $<0.05$ \\
DUB & 123 & 36 & 54 & & \\
Polyp & 17 & 11 & 20 & & \\
\hline
\end{tabular}

Table 9 showed the type of surgery performed as a definitive treatment, in maximum cases (230) TAH with BLSO was done, in 1 case NDVH was performed due to associated third degree uterocervical prolapse and in only 1 case which was suspected as malignant Wertheim's hysterectomy was done after confirmation on biopsy.

\begin{tabular}{ll} 
Table 9: Type of surgery & \\
\hline Type of surgery & No. of cases \\
\hline TAH with BLSO & 230 \\
TAH with LSO & 8 \\
TAH with RSO & 7 \\
VH & 3 \\
NDVH & 1 \\
Wertheim's hysterectomy & 1 \\
\hline TAH - Total abdominal hysterectomy, BLSO - Bilateral salpingo- \\
oophorectomy, LSO - Left sided oophorectomy, RSO - Right sided \\
oophorectomy, VH - Vaginal hysterectomy, NDVH - Non descend \\
vaginal hysterectomy
\end{tabular}


The New Indian Journal of OBGYN. 2021 (January-June);8(2)

\section{Discussion}

In our study out of 94 clinically diagnosed cases of fibroid, 19 cases could not be confirmed as fibroid on HPE and turned out to be adenomyosis in 6 cases, this reflects the over diagnosis of fibroid and under diagnosis of adenomyosis which may be due to the fact that fibroid is common finding among women with AUB. USG diagnosed 122 cases $(48.8 \%)$ as fibroid and 23 cases $(9.2 \%)$ as adenomyosis showing less diagnostic accuracy of USG for adenomyosis as compared to fibroid.

Correlating the clinical, USG and HPE finding, in our study almost all cases diagnosed clinically as fibroid were diagnosed on USG and final diagnosis which was made by HPE, leiomyoma was the most commonest which is comparable with the study of Gupta et $\mathrm{al}^{8}$ and Rizvi et al. ${ }^{9}$

As evident in our study 12 cases were diagnosed clinically as adenomyosis, 23 cases on USG and 40 cases were confirmed as adenomyosis on HPE. This correlation shows that less cases were diagnosed preoperatively and is usually diagnosed after hysterectomy on HPE, suggesting less diagnostic accuracy of clinical and USG diagnosis for adenomyosis, which may be due to lack of skill and experience in diagnosing adenomyosis.

In our study we also found that USG has high sensitivity $(86.8 \%)$ and specificity in diagnosing fibroid as compared to sensitivity $(26.3 \%)$ in diagnosing adenomyosis suggesting that USG is better in diagnosing fibroid but for adenomyosis investigation like MRI are more informative.

42 cases were diagnosed as bulky uterus on USG. Most of them 28 cases turned out to be normal, rest 9 cases (out of 14) turned out to be leiomyoma and in 5 cases were later diagnosed as adenomyosis, showing the wrong use of terminology of "bulky uterus" which may depict lack of confidence in identifying the pathology specifically. Out of 36 cases which were labeled normal on USG, most of them (27 cases) were confirmed to be normal on HPE showing better specificity (79.2\%) of USG to detect normal uterus (high negative predictive value - 89.1\%).

Out of 123 cases which were termed as DUB on clinical examination, 50 cases were confirmed as normal rest showed some detectable gross pathology on HPE. Though this could be because of lack of examiner's experience and skill but still it indicates that not all pathologies can be accurately diagnosed by clinical examination hence patients of DUB should be properly investigated and evaluated to reduce its morbidity.

\section{Conclusion}

On conducting this study, we concluded that enhancement in the skill and experience of examiner will go a long way in giving better and more accurate clinical diagnosis of AUB cases for timely intervention and management of AUB in perimenopausal women. We also concluded that training and increasing experience with diagnostic skill of ultrasonologist will definitely lead to specific and appropriate diagnosis of organic causes of AUB along with increased diagnosis of cases of adenomyosis. In view of sensitivity and specificity of clinical and USG diagnosis, we concluded that HPE remains the gold standard in diagnosis of AUB. AUB in perimenopausal age group seems to be a diagnostic challenge due to its wide range of causes so a comprehensive clinico-radiopathological study will be helpful in arriving at correct diagnosis.

\section{Conflict of interest: None. Disclaimer: Nil.}

\section{References}

1. Fraser IS, Critchley HO, Munro MG, Broder M. Can we achieve international agreement on terminologies and definitions used to describe abnormalities of menstrual bleeding? Hum. Reprod. 2007 Mar; 22(3): 635-43.

2. Talukdar B, Mahela S. Abnormal uterine bleeding in perimenopausal women: Correlation with sonographic findings and histopathological examination of hysterectomy specimens. J Midlife Health. 2016; 7(2): 73-7.

3. Rubin B, Crosignani PG. Review and guidelines on dysfunctional uterine bleeding. Study group of the European Society of Human Reproduction and Embryology. Hum Reprod. 1990; 5: 637-38.

4. Fraser IS, Sugurtekin U. Defining menstrual disturbances. In: Maclean A, O’Brien PMS, editors. Study Group on Menstrual Disorders. Royal College of Obstetricians and Gynaecologist. pp. 141-52.

5. Cameron IT. Dysfunctional uterine bleeding. In: Drife JO. (ed). Dysfunctional uterine bleeding and menorrhagia. Bailliere's Clin Obstet Gynaecol. 1989; 3: 315-28.

6. Speroff L, Glass RH, Kase NG. Clinical gynecologic endocrinology and infertility. 6th ed. Baltimore: Lippincott Williams \& Wilkins; 1999. pp. 201-38.

7. Nicula R, Costin N. Management of endometrial modifications in perimenopausal women. Clujul Med. 2015; 88(2):101-10. 
The New Indian Journal of OBGYN. 2021 (January-June);8(2)

8. Gupta A, Rathore AM, Manaktala U, Rudingwa P. Evaluation and histopathological correlation of abnormal uterine bleeding in perimenopausal women. IJBAR. 2013; 4(8): 509-13.

9. Rizvi G, Pandey H, Pant H, Chufal SS, Pant P. Histopathological correlation of adenomyosis and leiomyoma in hysterectomy specimens as the cause of abnormal uterine bleeding in women in different age groups in the Kumaon region: A retroprospective study. J Mid life Health. 2013; 4: 27-30.

\section{Roma Sharma ${ }^{1}$, Achala Sahai ${ }^{2}$}

${ }^{1}$ Senior Resident, Department of Obstetrics and Gynaecology, Gajra Raja Medical College, Gwalior, Madhya Pradesh, India; ${ }^{2}$ Associate Professor, Department of Obstetrics and Gynaecology, Gajra Raja Medical College, Gwalior, Madhya Pradesh, India. 